\title{
The Need for Integrating the Service Sector into the Innovative Systems of Resource Regions
}

\author{
Valeriy Kryukov ${ }^{1}$, and Anatoliy Tokarev ${ }^{1, *}$ \\ ${ }^{1}$ Institute of Economics \& Industrial Engineering, 63009017 Ac. Lavrentiev Av., Novosibirsk, Russia
}

\begin{abstract}
In the article it is proved that the service sector is the most important element of innovative systems for resource (primarily oil and gas) regions. It is shown that it is a leader and a link in the generation, integration and use in practice of local and global knowledge with respect to the exploration and production of hydrocarbon raw materials. Its integration into innovative systems of resource regions is one of the most important tasks for the authorities of these regions.
\end{abstract}

\section{Introduction}

The extraction of hydrocarbon raw materials is of great importance for the social and economic development of Russia and its raw material regions. For the successful operation and development of the oil and gas complex the effective service sector which provides a wide range of services is necessary. Service sector in the oil and gas sector (oilfield services) include a number of activities, such as: drilling wells; seismic research and geophysical work; current and major repair of wells; construction of infrastructure; application of enhanced oil recovery methods and intensification of production.

Increasing the role of the service sector in modern conditions is due to the fact that the world oil business is moving towards a structure in which oil and gas companies have become more system integrators, focusing on access to subsoil resources, securing financing and organizing production processes. At the same time, the main part of the exploration and development of the fields is performed by third-party service companies. This transformation is due, among other things, to an increase in the technological complexity of hydrocarbon production processes.

In modern conditions, the generation of knowledge, development and use of many new technologies in the exploration and production of hydrocarbon raw materials occurs either on the initiative or with the participation of service companies. Oil service companies play a leading role in the development and implementation of more than $60 \%$ of new technologies, as well as in obtaining about $80 \%$ of patents directly related to production technologies [1]. Since "knowledge is the most important strategic resource and learning is the most important process" [2], the role and importance of service in many aspects is increasing: from generation of knowledge to participation in solving social and economic problems of resource territories [3].

\footnotetext{
* Corresponding author: anatoli-3@yandex.ru
} 
Intellectual, knowledge-intensive service, even if the cost of services is high, can significantly reduce both the marginal cost of a unit of reserves and the cost of production. For example, thanks to modern technologies (including the wider use of horizontal wells), the use of accurate information on the properties and structure of deposits, one high-tech well is made instead of several ones, but it provides higher productivity and, accordingly, profitability of production. The role of such technologies is very significant, since the cost of drilling is about half of the total volume of capital investment in production. Within the service sector, the prerequisites for faster application of new technical solutions and innovations are created, and the demand for highly skilled personnel is increasing.

Reducing the unit cost of exploration and production actually leads to an increase in the resource base of hydrocarbon production. This is due to the fact that prerequisites arise, firstly, to prolong production at mature facilities (which determines, among other things, significant positive social effects, primarily at the regional level); secondly, to involve new subsoil areas in the economic turnover.

Reducing production costs leads to an increase in profits and, accordingly, the tax on profits paid to the budgets. At the same time in Russia, most of this tax is directed to regional budgets. The increase in the resource base for the production of hydrocarbons also contributes to the growth of tax base as a result of the expansion of the profitable facilities range. Thus, the service not only generates tax payments, but also creates prerequisites for their formation and growth in extractive industries.

At the same time, the development of resources of new types of hydrocarbon raw materials, development of deposits in new promising regions (Eastern Siberia, shelf) makes new requirements for the organization of oilfield service. Thus, in new regions and provinces there are tasks not only to attract national and global players, but also to develop local companies with a set of specific local knowledge and skills. New sources of hydrocarbons are more local in nature. Their features increasingly exclude traditional schemes of field development. This circumstance opens up opportunities for small and medium-sized innovative-oriented companies with specific knowledge of the features of such local facilities.

Therefore, the problems of integrating a service (as a key generator and carrier of new knowledge and technologies) into innovative systems of resource regions are becoming more relevant. The specific nature of the resource sector is related to the fact that the development of new technologies, their approbation and implementation require close "connection" to specific development facilities - minefields and deposits. At the same time, the effect of geographical proximity [4] to specific development facilities is an important factor for the development of regional and local services.

\section{Materials and methods}

In many countries, regional innovation systems are becoming increasingly important factors in social-and-economic development. Various approaches to the formation of territorial innovation models are being implemented [5]. Russian regions being in the mainstream of global trends are also making attempts to create and develop their innovative systems. Resource regions are no exception in this process. Considering the importance of mining for the Russian economy, the scale and importance of large vertically integrated companies, the resource entities of the Russian Federation face difficult tasks of effective participation in innovative processes.

The article examines the possibilities of applying different approaches to the formation and development of regional innovation systems in the part that works for the needs of the resource sector. Using the methods of cluster analysis, the resource regions of Russia (subjects of the Federation for which mining is of key importance) have been identified. At 
the same time official data of state statistics were used, including the structure of the gross regional product by types of economic activity, the structure of industrial production by the subjects of the Federation. Further, for the resource regions, the role of the service sector was assessed on the basis of data on the tax payments of the service sector from the Federal Tax Service. The data on the organizational structure of the extractive sector as well as the scientific and educational complex working for the needs of the extractive industry were also analyzed.

Service, to wide extent, is a leader and a link in the generation, integration and use in practice of local and global knowledge in relation to exploration and production. So, large service companies conduct fundamental research to generate new knowledge for effective resource development. But this knowledge should be "connected" in space to specific objects, almost all of which have their own specifics (which in many respects determines the features of innovation processes in the industry sector under consideration). The service can work more effectively when it is integrated not only in global processes, but also in local innovation systems.

The acquisition and integration of global and local knowledge in the formation and development of regional innovation systems [6] in the part that works for the needs of the resource sector can occur within the framework of several models [7]. Depending on the nature of the "learning" processes, an endogenous (local) model, a network (flexible) and an exogenous (external) model of the formation and development of an industry component of regional innovation systems can be implemented. This structure of the sectoral component creates prerequisites for a clearer understanding of the specifics of innovation processes in resource regions and for the development of practical recommendations.

\section{Results and Discussion}

\subsection{Endogenous (local) model}

Within the framework of the endogenous model, innovative activity for the needs of extractive industries is mainly based on the localized process of "learning" (obtaining, generating and using knowledge), supported by the effects of geographical and social proximity of participants with relatively weak interaction with the external environment (including the national innovation system, scientific and educational complex - SEC including scientific research, industry, design institutes, universities). In the long term, most companies cannot rely only on localized "training", they must have strong links with a more universal, codified knowledge, for example, within the national innovation system.

\subsection{Network (flexible) model}

Within the framework of a network model, innovation activity is also characterized primarily by localized, interactive "learning". At the same time, innovative development is more systematic, including the participation of regional authorities. In this case, the local (regional) innovation infrastructure, research and design institutes, universities are widely used. This model is potentially seen as more rational and promising.

To implement it effectively, a developed regional innovation system is needed, in which local companies (including service companies) work closely with each other. Global knowledge is brought by large (national and foreign) mining and service companies. At the same time, an innovative infrastructure should be developed in the region to generate, efficiently transfer and use new knowledge (in particular about the features of the resource potential of the territory). 
A common modern tendency is that not only companies, but also individuals engineers and specialists - are increasingly participating in the processes of formation and dissemination of knowledge. So the flow and generation of new knowledge, learning processes (primarily within the framework of local and network models) can occur through a number of "channels":

- initiative innovations of employees in the production processes (when the experts themselves are interested in innovation, understanding that the competitiveness of their companies can have important social effects);

- knowledge transfer between specialists of local firms (personal contacts between employees of different firms - not only in the framework of production processes; participation in joint projects - advice from co-executors, transfer of workers from extractive companies to service companies, and vice versa);

- cooperation within the framework of local organizations and associations (which can be implemented including in the work of regional associations of service companies, which takes place, for example, in the Tyumen region).

In Russia, among the subjects of the Russian Federation that are trying to develop innovative systems (including those that are directly related to the extraction of resources) within the network model Tatarstan and the Tomsk region can be named. So Tatarstan, forming a network model, largely relies on the effects of geographical and social proximity of participants in innovation processes. The administration of the Tomsk region has been making long-term efforts to build long-term relations between the region's extractive industry, on the one hand, and the SEC, local suppliers of goods, equipment, services, on the other (since the mid-1990s with varying degrees of success).

The "launch" and successful development of the network model largely depends on the level of concentration of activities, one of the bases of which can be the presence of a branched and diverse service sector. For example, within the boundaries of the "Greater Stavanger" - the Norwegian center of the oil and gas complex on the North Sea shelf more than 500 innovative-oriented service firms successfully operate. In this case, the effects of not only geographic but also organizational "proximity" work, when it is more convenient and efficient for new firms to place their production in this cluster [8].

\subsection{Exogenous (external) model}

Within the framework of the exogenous model, innovation activity relies more on cooperation with actors outside the region (external model). The existing elements of an innovative system working for the needs of the extractive industry are more integrated into national and/or international innovation processes. The interaction of participants is mainly based on a linear principle, since cooperation involves mainly specific innovative organizations to develop and generate more "radical" innovations using scientific, formal knowledge. Such cooperation can be stimulated when participants have a similar education and knowledge (and they do not necessarily belong to the same local community) [9].

Among the Russian regions the innovative processes in the gas industry of the YamaloNenets Autonomous District correspond to such model to a certain extent. The reasons for this situation include the rigid centralization of innovation processes within Gazprom (the effect of organizational proximity), the need for "radical" innovations for the effective development of new resources, primarily the Valanginian and Achimov deposits, the relatively weak development of regional SEC (largely due to objective reasons related to the complex climate, the history of its formation and development).

A typical example is the activity of Gazprom on involving Achimov gas deposits in the economic turnover in the Yamal-Nenets Autonomous District. These deposits are at the depths of about $4000 \mathrm{~m}$ and have a much more complex geological structure (denser rocks, 
high pressures and temperatures) compared to the main development facilities at present Cenomanian gas deposits (depth 1100-1700 m). To optimize the technologies for the development of these deposits in the Urengoy field, Gazprom and German company Wintershall (a subsidiary of BASF) set up a joint venture, Achimgaz, which combines the knowledge, competencies and experience of these companies to develop complex deposits.

There cannot be a single model of innovation development in the Russian resource regions. Such models are expedient to form and develop taking into account a wide range of features: the level of economy development, human capital and SEC; already existing knowledge about the resource base; "history" of the formation and development of the mining complex (including its most important innovation component - service).

\section{Conclusion}

The development of resources of new types of hydrocarbon raw materials, the development of deposits in new promising regions, the development of complex facilities in "mature" regions make new requirements to the organization and structure of the service - as the main driver of the innovative development of the oil and gas complex.

In the new promising areas and regions, there is the task of balancing a mix of local companies and "players" based in other regions. To develop new types of hydrocarbons an increasing emphasis on the development and application of innovative technologies is necessary. That requires a flexible combination of local and global knowledge and players in the service business.

Service (taking into account its scale and innovative character) is potentially an important element of regional innovation systems. The task for many resource regions is to maximize the use of its potential for the development of the regional economy, to integrate the extractive industries in general, and service as a driver of innovation processes, in particular, into innovative systems of resource territories $[10,11]$.

\section{References}

1. R. Perrons, J. of Petr. Sci. Engin., 124, 301 (2014)

2. B.-A. Lundvall, The economics of knowledge and learning // Product Innovation, Interactive Learning and Economic Performance (Emerald Group Publishing Limited, 2004)

3. V. Kryukov, A. Tokarev \& V. Shmat, Problems of Economic Transition, 58:2, 73 (2016)

4. R. Shearmur, The Canadian Geographer, 54:1, 46 (2010)

5. F. Moulaert, F. Sekia, Regional Studies, 37:3, 289 (2003)

6. B. Asheim, A. Isaksen, J. of Technology Transfer, 27:1, 77 (2002)

7. B. Asheim, A. Isaksen, Location agglomeration and innovation: Towards regional innovation systems in Norway? (STEP group, Report, 1996)

8. R. Boshma, Regional Studies, 39(1), 61 (2005)

9. A. Isaksen, J. Karlsen, Industry and Innovation, 19:3, 249 (2012)

10. V. Kryukov, A. Tokarev \& S. Yenikeyeff, Plundered nations? Successes and failures in natural resource extraction, (London: Palgrave Macmillan, 2011)

11. A. Tokarev, Problems of Economic Transition, 59:1-3, 100 (2017) 